\title{
Erratum
}

\section{Erratum: Altimus et al., "The Next 50 Years of Neuroscience”}

In the article "The Next 50 Years of Neuroscience" by Cara M. Altimus, Bianca Jones Marlin, Naomi Ekavi Charalambakis, Alexandra Colón-Rodriquez, Elizabeth J. Glover, Patricia Izbicki, Anthony Johnson, Mychael V. Lourenco, Ryan A. Makinson, Joseph McQuail, Ignacio Obeso, Nancy Padilla-Coreano, and Michael F. Wells, and for Training Advisory Committee, which appeared on pages 101-106 of the January 2, 2020 issue, part of the author line appeared incorrectly. Alexandra Colón-Rodriquez's name should appear as Alexandra Colón-Rodríguez.

This has been updated online. The corrected author line appears below.

Cara M. Altimus, Bianca Jones Marlin, Naomi Ekavi Charalambakis, Alexandra Colón-Rodríguez, Elizabeth J. Glover, Patricia Izbicki, Anthony Johnson, Mychael V. Lourenco, Ryan A. Makinson, Joseph McQuail, Ignacio Obeso, Nancy Padilla-Coreano, and Michael F. Wells, for Training Advisory Committee

DOI: $10.1523 / J N E U R O S C I .0103-20.2020$

\section{Erratum: McNair et al., "Deletion of Neuronal GLT-1 in Mice Reveals Its Role in Synaptic Glutamate Homeostasis and Mitochondrial Function"}

In the article "Deletion of Neuronal GLT-1 in Mice Reveals Its Role in Synaptic Glutamate Homeostasis and Mitochondrial Function" by Laura F. McNair, Jens V. Andersen, Blanca I. Aldana, Michaela C. Hohnholt, Jakob D. Nissen, Yan Sun, Kathryn D. Fischer, Ursula Sonnewald, Nils Nyberg, Sophie C. Webster, Kush Kapur, Theresa S. Rimmele, Ilaria Barone, Hannah Hawks-Mayer, Jonathan O. Lipton, Nathaniel W. Hodgson, Takao K. Hensch, Chiye J. Aoki, Paul A. Rosenberg, and Helle S. Waagepetersen, which appeared on pages 4847-4863 of the June 19, 2019 issue, the authors would like to note that in Figure $5 B$ and Table 2, the unit should be nmol/mg protein instead of $\mu \mathrm{mol} / \mathrm{mg}$ protein. Additionally, in Figure $6 \mathrm{~A}$, the unit should be changed from $\mu \mathrm{mol} / \mathrm{mg} \mathrm{protein} / \mathrm{h}$ to $\mathrm{nmol} / \mathrm{mg}$ protein/h. These errors also occur on page 4857 in the top right paragraph, as well as page 4858 in the bottom left paragraph. The article has been updated online.

DOI: 10.1523/JNEUROSCI.3015-19.2019 